\title{
Gamma background measurements in the Boulby Underground Laboratory
}

\author{
Dariusz Malczewski $\cdot$ Jan Kisiel $\cdot$ Jerzy Dorda
}

Received: 1 March 2013/Published online: 15 May 2013

(c) The Author(s) 2013. This article is published with open access at Springerlink.com

\begin{abstract}
To determine background radiation levels that might influence experiments, we measured in situ gammaray emissions at ten locations in the Boulby Underground Laboratory. For gamma radiation in the energy range of $7-2,734 \mathrm{keV}$, the counts varied from 6.5 to $28 \gamma^{-1}$. For measurements inside the Lab, the arithmetic mean was $24 \gamma \mathrm{s}^{-1}$. The sedimentary rocks that surrounded the Lab, halite and mudstone, were characterized by very low activity concentrations of uranium $\left(0.8-7.1 \mathrm{~Bq} \mathrm{~kg}^{-1}\right)$ and thorium $\left(0.6-3.9 \mathrm{~Bq} \mathrm{~kg}^{-1}\right)$.
\end{abstract}

Keywords Gamma-ray spectrometry - Gamma background · Gamma fluxes · Underground laboratory

\section{Introduction}

The Boulby Underground Laboratory of the Institute of Underground Science (IUS), University of Sheffield, is located deeper underground than any other underground research center in Europe [1]. The Laboratory is located 1,100 $\mathrm{m}$ below ground in the Boulby Mine (NE England). The total area of the $\mathrm{Lab}$ is over $1,000 \mathrm{~m}^{2}$, including associated facilities. The scientific programs at IUS comprise dark matter detection and astroparticle physics [2]. Because the experiments represent investigations of extremely rare events, it is necessary to determine precisely

D. Malczewski ( $₫)$

Faculty of Earth Sciences, University of Silesia, Bedzinska 60,

41-200 Sosnowiec, Poland

e-mail: dariusz.malczewski@us.edu.pl

J. Kisiel · J. Dorda

Institute of Physics, University of Silesia, Uniwersytecka 4,

40-007 Katowice, Poland the natural radioactivity background levels. After cosmic rays, the most important sources of background radiation comprise the decay of primordial radionuclides, including ${ }^{40} \mathrm{~K}$, ${ }^{232} \mathrm{Th}$, and ${ }^{238} \mathrm{U}$ in rocks, building materials, and materials used in constructing detectors [3]. The main sources of background radiation are the neutrons that originate from $(\alpha, n)$ reactions and the spontaneous fission of $U$ and $T h$, which can imitate some of the signals expected from the experiments. In this study, we performed in situ gamma-ray measurements inside the IUS, and we measured samples of the parent rocks that surrounded the Lab, which consisted mainly of halite $(\mathrm{NaCl})$ with minor impurities of sylvite $(\mathrm{KCl})$ and mudstone ( ca $92 \mathrm{wt} \%$ $\mathrm{SiO}_{2}$ ).

\section{Materials and methods}

The measurements were made in 2006. We measured the background gamma radiation in the IUS in situ with a portable gamma-ray spectrometry (Fig. 1). The GX3020 system consisted of a coaxial HPGe detector (32\% efficiency, $59 \mathrm{~mm}$ crystal length, $56.6 \mathrm{~mm}$ diameter) with a cryostat mounted on a tripod or a special table, a $50 \times 180 \mathrm{~mm}$ collimator (diameter $80 \mathrm{~mm}$ ), a multichannel buffer (InSpector 2000 DSP), and a laptop computer. The detector had a bias voltage of $4,000 \mathrm{~V}$ and energy resolutions of $0.8 \mathrm{keV}$ at $122 \mathrm{keV}$ and $1.7 \mathrm{keV}$ at $1.33 \mathrm{MeV}$. For efficiency calibrations and determination of radionuclides, we used In Situ Object Counting Software (ISOCS), Laboratory Sourceless Calibration Software (LabSOCS), and Genie 2000 v.3. software packages. The ISOCS software was designed to generate efficiency calibrations for many types of large objects, walls, and floors based on mathematical modeling instead of calibration 
sources. The total duration of a single measurement varied from about 1 to $67 \mathrm{~h}$.

Samples of halite and mudstone collected from the longwalls outside the Lab were crushed. Several months after collection, they were placed in a $450 \mathrm{~cm}^{3}$ Marinelli beaker, and measured with the same GX3020 HPGe detector in a lead and copper shield $(60 \mathrm{~mm})$. The energy calibration of the spectrometer was carried out with homogeneously dispersed ${ }^{241} \mathrm{Am},{ }^{109} \mathrm{Cd},{ }^{139} \mathrm{Ce},{ }^{57} \mathrm{Co},{ }^{60} \mathrm{Co}$, ${ }^{137} \mathrm{Cs},{ }^{113} \mathrm{Sn},{ }^{85} \mathrm{Sr},{ }^{88} \mathrm{Y}$, and ${ }^{203} \mathrm{Hg}$ radioisotopes embedded in silicone resin (certificate source type Marinelli Beaker Standard Source [MBSS], supplied by the Czech Metrological Institute). These measurements were performed at the Laboratory of Natural Radioactivity (Faculty of Earth Sciences, University of Silesia).

\section{Locations of in situ measurements}

Location point 1 was in the transport hall (Fig. 1.1). The end cap of the detector was mounted $90 \mathrm{~cm}$ above the drift level, $10 \mathrm{~m}$ from the transport entrance, and $2 \mathrm{~m}$ from the left longwall (facing the ground).

Location point 2 was in the HPGe detector room, with the detector facing the floor. The detector was placed $90 \mathrm{~cm}$ above the floor and $2 \mathrm{~m}$ from the side walls (Fig. 1.2).
Location point 3 was in a drift, $29 \mathrm{~m}$ to the left side of the main Lab entrance (Fig. 1.3). The detector was set on a table, oriented horizontally, $10 \mathrm{~cm}$ from the longwall, and $90 \mathrm{~cm}$ above the drift level.

Location point 4 was near the DRIFT detector. The spectrometer was placed on a tripod at 1.6 and $3.6 \mathrm{~m}$ from the side walls, facing the floor, at $90 \mathrm{~cm}$ above the floor plane (Fig. 1.4).

Location point 5 was in the transport hall (Fig. 1.5). The detector was mounted horizontally on a table, $10 \mathrm{~cm}$ from the longwall, and $90 \mathrm{~cm}$ above the drift level.

Location point 6 was in the Main Lab, $6.5 \mathrm{~m}$ from the service entrance, and $2.5 \mathrm{~m}$ from the side walls. The detector was set horizontally on a table, $90 \mathrm{~cm}$ above the floor and directed to the inside of the Lab. This geometry ensured close to a $4 \pi$ field of view of the entire room (Fig. 1.6).

Location point 7 was in an area called the "H area". The spectrometer was set on a tripod, facing down, $90 \mathrm{~cm}$ above the drift level, and $3 \mathrm{~m}$ from the side walls (Fig. 1.7).

Location point 8 was in the transport hall. The detector was equipped with a collimator; it was mounted on a table, set horizontally at $5 \mathrm{~cm}$ from the longwall, $90 \mathrm{~cm}$ above the drift level, and $8.5 \mathrm{~m}$ from the Lab exit (Fig. 1.8).

Location point 9 was the same as point 6 , except that the detector was facing down and placed on a tripod at $90 \mathrm{~cm}$ above the floor plane (Fig. 1.9).
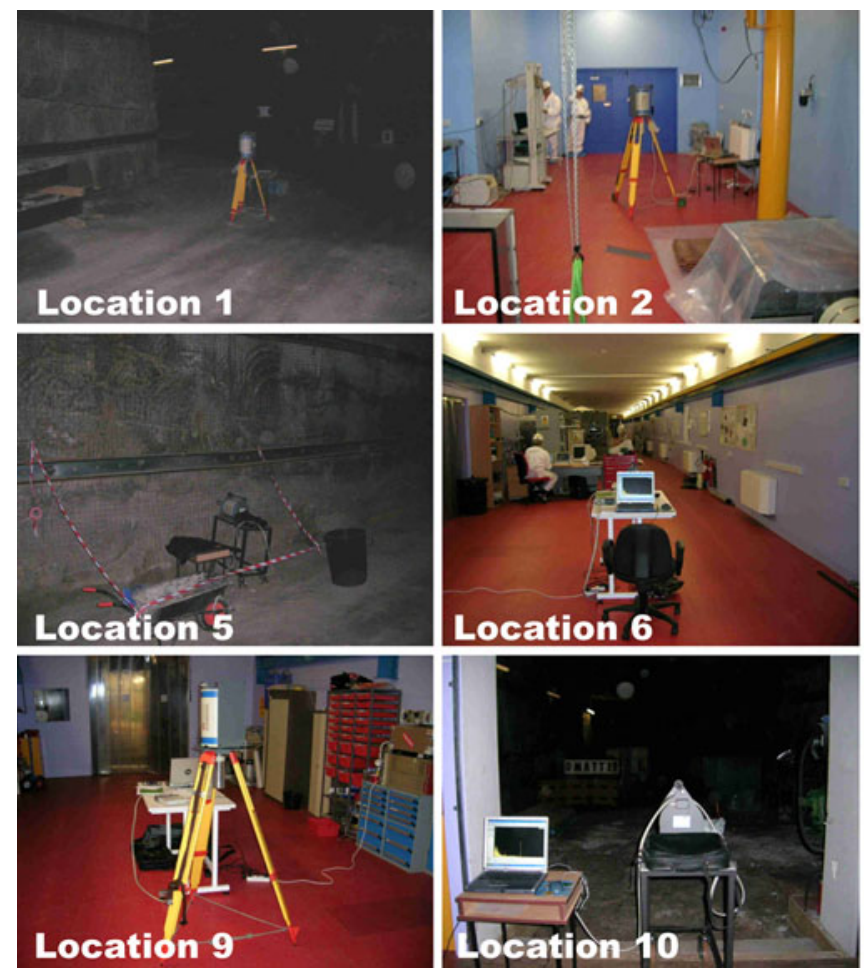
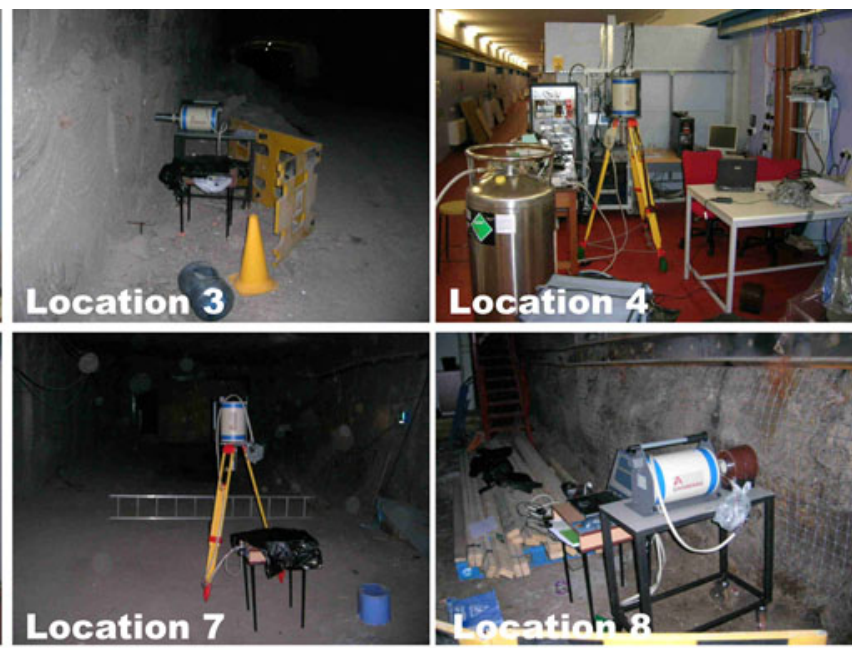

Fig. 1 Locations and configurations of in situ measurements 

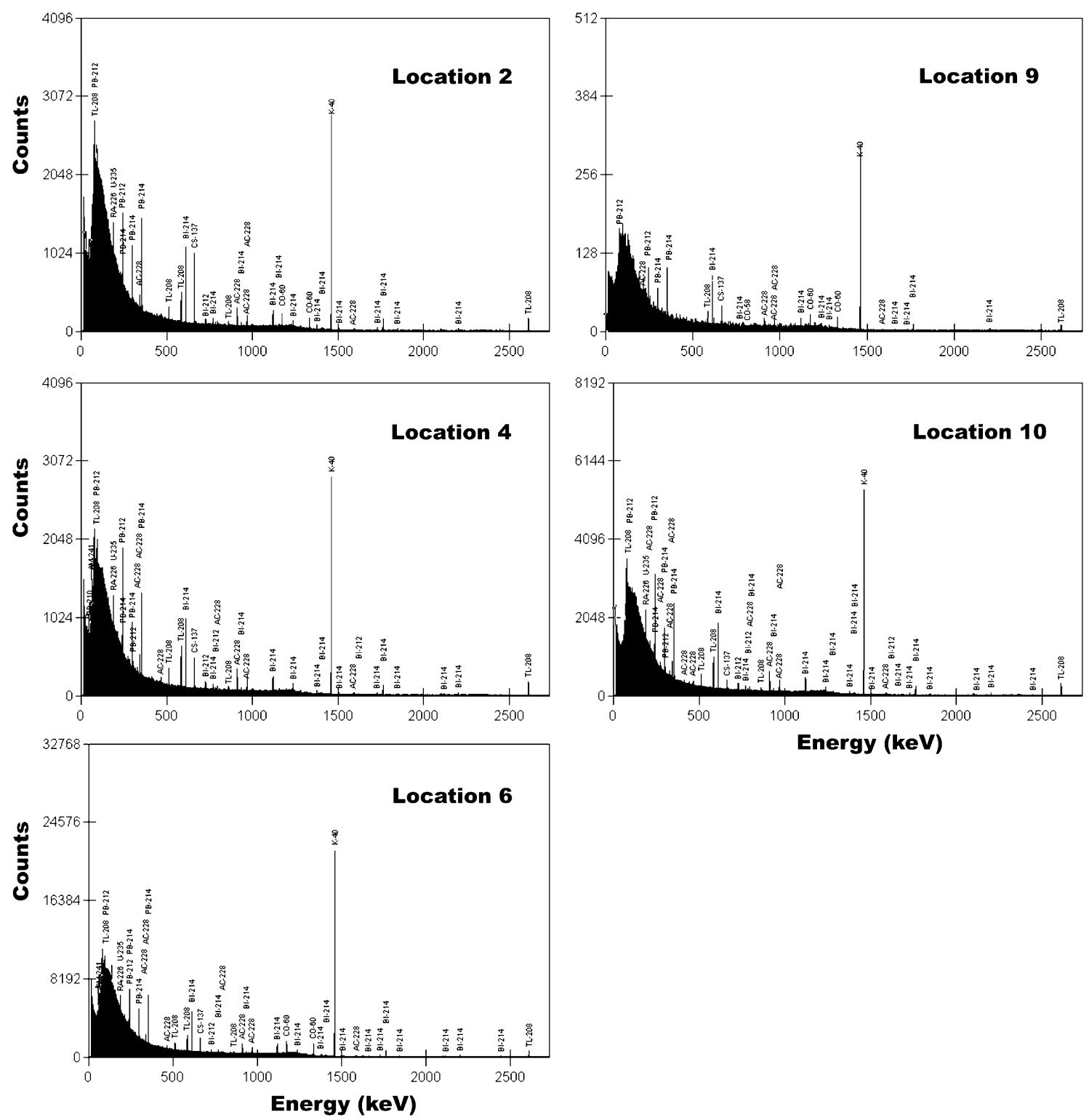

Fig. 2 In situ gamma-ray spectra at specified locations inside the Lab. The characteristic gamma-ray emitters are indicated above the corresponding peaks

Location point 10 was at the border between the Lab area and the transport hall (Fig. 1.10). The detector was on a table, set horizontally, pointing into the transport hall, placed at $130 \mathrm{~cm}$ above the ground level.

The gamma-ray spectra, measured at locations inside and outside the Lab, are shown in Figs. 2 and 3, respectively.

\section{Results and discussion}

The count rates $\left(\gamma \mathrm{s}^{-1}\right)$ at all location points are listed in Table 1 . The gamma-ray fluxes $\left(\gamma \mathrm{cm}^{-2} \mathrm{~s}^{-1}\right)$ from location
8 are given in Table 2. The count rates in the main gamma peaks and the gamma fluxes from these peaks at location 8 are presented in Tables 3 and 4, respectively. Table 5 summarizes the results of the activity measurements in halite and mudstone.

In situ measurements

Inside the Lab (locations 2, 4, 6, 9, and 10), in the energy range of 7.4-2734.2 keV, the total count rates varied from $18 \mathrm{\gamma} \mathrm{s}^{-1}$ (location 4) to $28 \mathrm{\gamma} \mathrm{s}^{-1}$ (locations 6 and 9), with an arithmetic mean of 24(4) $\gamma \mathrm{s}^{-1}$ (Table 1; Fig. 4a). 

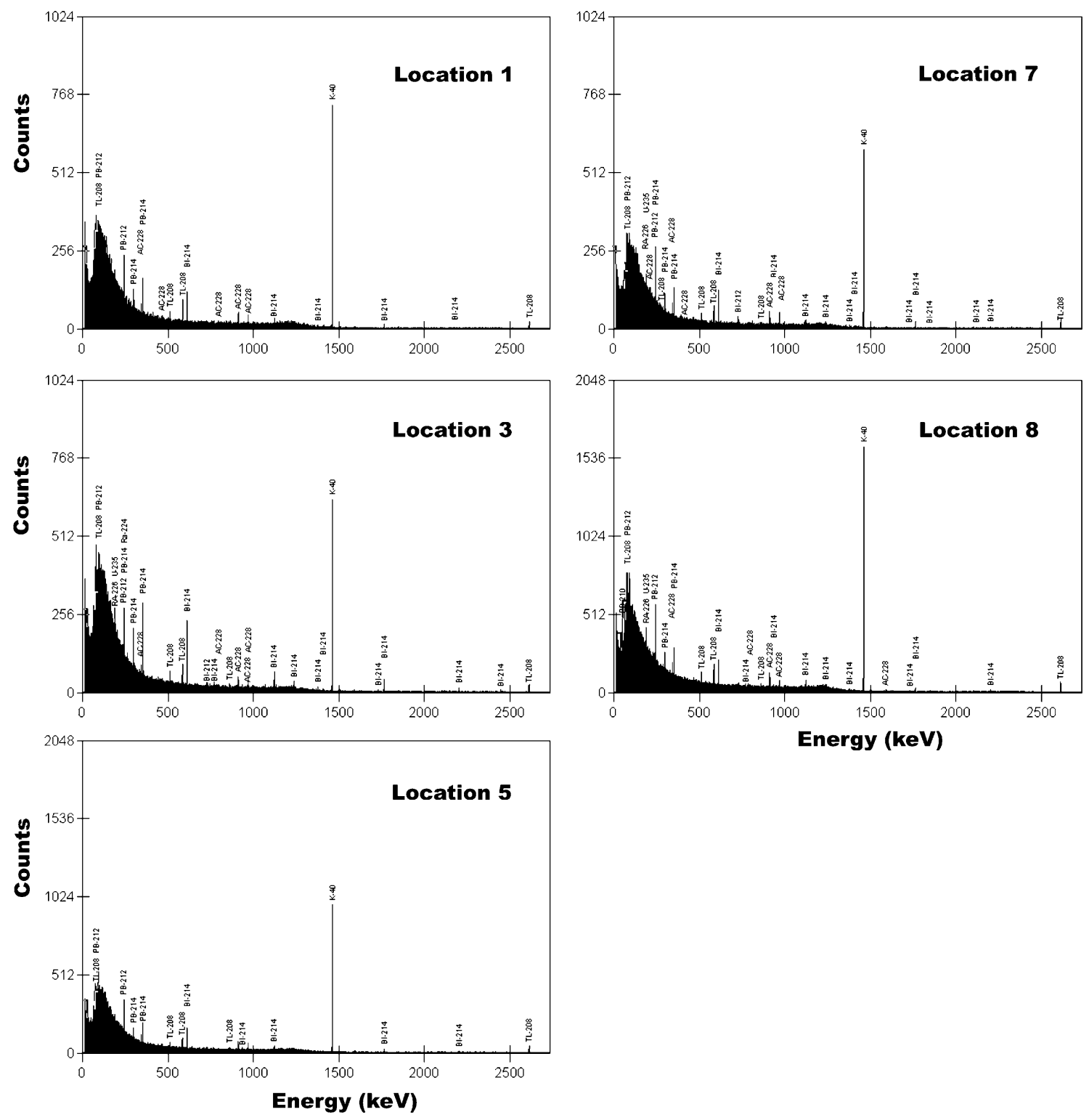

Fig. 3 In situ gamma-ray spectra at specified locations outside the Lab. The characteristic gamma-ray emitters are indicated above the corresponding peaks

Outside the Lab (locations 1, 3, 5, 7, and 8), in the same energy range, the total count rates varied from 6.5 (location 8) to $\sim 23 \gamma^{-1}$ (location 1). The arithmetic mean for measurements taken without a collimator (locations 1, 3, 5, and 7) was 20(3) $\gamma \mathrm{s}^{-1}$ (Table 1; Fig. 4b). The average count rate inside the Lab was slightly higher than that outside the Lab. This indicated that building materials, detectors, and calibration sources contributed an additional gamma background. As expected, the highest count rates (between 7.4 and $249.8 \mathrm{keV}$ ) contributed, on average, $66 \%$ of the total counts (0.66 fractional contribution; Table 5) at all measurement locations. In the higher energy ranges, the count rates noticeably decreased as the energy range increased. The average fractional contributions to the total counts were $0.16,0.11,0.07,5 \times 10^{-3}$, and $4 \times 10^{-3}$ for ranges 250-500, 501-1005, 1006-1556, 1556-2056, and $2056-2734 \mathrm{keV}$, respectively (Table 1; Fig. 5). For measurements taken with a collimator (location 8), the total gamma flux was $0.128 \gamma \mathrm{cm}^{-2} \mathrm{~s}^{-1}$ (Table 2). Similar to the count rates, the fractional contributions of the gamma fluxes rapidly decreased as the energy ranges increased; they were on the order of $10^{-2}$ in the $250-1,556 \mathrm{keV}$ range, and $10^{-4}$ in the $1,556-2,734 \mathrm{keV}$ range. 
Table 1 Count rates $\left(\gamma \mathrm{s}^{-1}\right)$ in particular energy ranges

\begin{tabular}{|c|c|c|c|c|c|c|c|}
\hline Location & $\begin{array}{l}7.4-2734.2 \\
\mathrm{keV}\end{array}$ & $\begin{array}{l}7.4-249.8 \\
\mathrm{keV}\end{array}$ & $\begin{array}{l}250.2-500.4 \\
\mathrm{keV}\end{array}$ & $\begin{array}{l}500.8-1005.2 \\
\mathrm{keV}\end{array}$ & $\begin{array}{l}1005.6-1555.8 \\
\mathrm{keV}\end{array}$ & $\begin{array}{l}1556.2-2055.8 \\
\mathrm{keV}\end{array}$ & $\begin{array}{l}2056.2-2734.2 \\
\mathrm{keV}\end{array}$ \\
\hline $1(9483)^{\mathrm{a}}$ & $22.67(5)$ & 14.92 & 3.38 & 2.42 & 1.78 & 0.094 & 0.075 \\
\hline $2(68433)$ & $20.11(2)$ & 13.82 & 3.03 & 1.96 & 1.13 & 0.097 & 0.074 \\
\hline $3(12713)$ & $20.52(4)$ & 14.06 & 3.06 & 1.97 & 1.24 & 0.123 & 0.073 \\
\hline $4(67831)$ & $17.99(2)$ & 11.97 & 2.85 & 1.88 & 1.10 & 0.105 & 0.085 \\
\hline 5 (13016) & 21.77(4) & 14.24 & 3.35 & 2.35 & 1.66 & 0.096 & 0.078 \\
\hline $6(242134)$ & $27.80(1)$ & 18.15 & 4.37 & 2.99 & 2.08 & 0.121 & 0.089 \\
\hline 7 (11800) & $14.91(4)$ & 9.89 & 2.22 & 1.56 & 1.10 & 0.075 & 0.060 \\
\hline $8(69068)$ & $6.46(1)$ & 3.93 & 1.08 & 0.82 & 0.55 & 0.036 & 0.029 \\
\hline 9 (3539) & $27.76(9)$ & 18.26 & 4.29 & 2.96 & 2.04 & 0.114 & 0.089 \\
\hline $10(77778)$ & $25.98(2)$ & 16.90 & 4.21 & 2.83 & 1.74 & 0.163 & 0.130 \\
\hline
\end{tabular}

Measurement at location 8 was performed using a collimator

${ }^{\text {a }}$ Measurement time (s)

Table 2 Gamma flux in $\gamma \mathrm{cm}^{-2} \mathrm{~s}^{-1}$ in the specified energy ranges measured at location 8

\begin{tabular}{llllllll}
\hline Location & $\begin{array}{l}7.4-2734.2 \\
\mathrm{keV}\end{array}$ & $\begin{array}{l}7.4-249.8 \\
\mathrm{keV}\end{array}$ & $\begin{array}{l}250.2-500.4 \\
\mathrm{keV}\end{array}$ & $\begin{array}{l}500.8-1005.2 \\
\mathrm{keV}\end{array}$ & $\begin{array}{l}1005.6-1555.8 \\
\mathrm{keV}\end{array}$ & $\begin{array}{l}1556.2-2055.8 \\
\mathrm{keV}\end{array}$ & $\begin{array}{l}2056.2-2734.2 \\
\mathrm{keV}\end{array}$ \\
\hline 8 & 0.128 & $7.82 \times 10^{-2}$ & $2.15 \times 10^{-2}$ & $1.63 \times 10^{-2}$ & $1.10 \times 10^{-2}$ & $7.14 \times 10^{-4}$ & $5.83 \times 10^{-4}$ \\
\hline
\end{tabular}

Table 3 Individual peak sizes in counts per seconds (CPS) for all 10 measurement locations

\begin{tabular}{|c|c|c|c|c|c|c|}
\hline Location & $\begin{array}{l}351.9 \mathrm{keV} \\
{ }^{214} \mathrm{~Pb}\left({ }^{238} \mathrm{U}\right) \\
1.18 \mathrm{keV}^{\mathrm{a}}\end{array}$ & $\begin{array}{l}609.3 \mathrm{keV} \\
{ }^{214} \mathrm{Bi}\left({ }^{238} \mathrm{U}\right) \\
1.32 \mathrm{keV}\end{array}$ & $\begin{array}{l}911.6 \mathrm{keV} \\
{ }^{228} \mathrm{Ac}\left({ }^{232} \mathrm{Th}\right) \\
1.59 \mathrm{keV}\end{array}$ & $\begin{array}{l}1460.8 \mathrm{keV} \\
{ }^{40} \mathrm{~K} \\
1.83 \mathrm{keV}\end{array}$ & $\begin{array}{l}2204.2 \mathrm{keV} \\
{ }^{214} \mathrm{Bi}\left({ }^{238} \mathrm{U}\right) \\
2.09 \mathrm{keV}\end{array}$ & $\begin{array}{l}2614.5 \mathrm{keV} \\
{ }^{208} \mathrm{Tl}\left({ }^{232} \mathrm{Th}\right) \\
2.29 \mathrm{keV}\end{array}$ \\
\hline 1 & $0.096^{\mathrm{b}}$ & 0.071 & 0.039 & 0.481 & $2.32 \times 10^{-3}$ & 0.019 \\
\hline 2 & 0.126 & 0.084 & 0.031 & 0.248 & $4.59 \times 10^{-3}$ & 0.017 \\
\hline 3 & 0.123 & 0.089 & 0.032 & 0.289 & $5.43 \times 10^{-3}$ & 0.015 \\
\hline 4 & 0.116 & 0.077 & 0.033 & 0.249 & $4.19 \times 10^{-3}$ & 0.020 \\
\hline 5 & 0.093 & 0.062 & 0.035 & 0.442 & $3.30 \times 10^{-3}$ & 0.021 \\
\hline 6 & 0.162 & 0.110 & 0.047 & 0.509 & $5.56 \times 10^{-3}$ & 0.020 \\
\hline 7 & 0.068 & 0.059 & 0.031 & 0.296 & $2.97 \times 10^{-3}$ & 0.014 \\
\hline 8 & 0.028 & 0.018 & 0.013 & 0.135 & $1.22 \times 10^{-3}$ & $6.19 \times 10^{-3}$ \\
\hline 9 & 0.144 & 0.105 & 0.048 & 0.493 & $5.37 \times 10^{-3}$ & 0.020 \\
\hline 10 & 0.165 & 0.126 & 0.054 & 0.413 & $6.60 \times 10^{-3}$ & 0.031 \\
\hline
\end{tabular}

${ }^{a}$ Full width at half maximum (FWHM)

${ }^{b}$ Estimated uncertainty of peak areas $\leq 8 \%$

Table 4 Gamma flux in $\gamma \mathrm{cm}^{-2} \mathrm{~s}^{-1}$ from the main gamma peaks at location 8

\begin{tabular}{|c|c|c|c|c|c|}
\hline $\begin{array}{l}351.9 \mathrm{keV} \\
{ }^{214} \mathrm{~Pb}\left({ }^{238} \mathrm{U}\right)\end{array}$ & $\begin{array}{l}{ }^{609.3 \mathrm{keV}} \\
{ }^{214} \mathrm{Bi}\left({ }^{238} \mathrm{U}\right)\end{array}$ & $\begin{array}{l}911.6 \mathrm{keV} \\
{ }^{228} \mathrm{Ac}\left({ }^{232} \mathrm{Th}\right)\end{array}$ & ${ }^{1460.8 \mathrm{keV}}$ & $\begin{array}{l}2204.2 \mathrm{keV} \\
{ }^{214} \mathrm{Bi}\left({ }^{238} \mathrm{U}\right)\end{array}$ & $\begin{array}{l}2614.5 \mathrm{keV} \\
{ }^{208} \mathrm{Tl}\left({ }^{232} \mathrm{Th}\right)\end{array}$ \\
\hline $1.18 \mathrm{keV}^{\mathrm{a}}$ & $1.32 \mathrm{keV}$ & $1.59 \mathrm{keV}$ & $1.83 \mathrm{keV}$ & $2.09 \mathrm{keV}$ & $2.29 \mathrm{keV}$ \\
\hline $5.57 \times 10^{-4 b}$ & $3.63 \times 10^{-4}$ & $2.61 \times 10^{-4}$ & $2.70 \times 10^{-3}$ & $2.42 \times 10^{-5}$ & $1.37 \times 10^{-4}$ \\
\hline
\end{tabular}

${ }^{\mathrm{a}}$ Full width at half maximum (FWHM)

${ }^{b}$ Estimated uncertainty of peak areas $\leq 8 \%$ 
Table 5 Measured ${ }^{40} \mathrm{~K},{ }^{232} \mathrm{Th}$, and ${ }^{238} \mathrm{U}$ activity concentrations in halite and mudstone

\begin{tabular}{lll}
\hline Halite & \\
\hline${ }^{40} \mathrm{~K}\left(\mathrm{~Bq} \mathrm{~kg}^{-1}\right)$ & ${ }^{232} \mathrm{Th}\left(\mathrm{Bq} \mathrm{kg}^{-1}\right)$ & ${ }^{238}{\mathrm{U}\left(\mathrm{Bq} \mathrm{kg}^{-1}\right)}^{c}$ \\
\hline $11(1)$ & $0.6(1)$ & $0.40(9)$ \\
$\mathrm{K}(\%)$ & ${ }^{232} \mathrm{Th}(\mathrm{ppm})$ & $238 \mathrm{U}(\mathrm{ppm})$ \\
$0.036(3)$ & $0.16(2)$ & $0.032(7)$ \\
\hline Mudstone & & \\
\hline${ }^{40} \mathrm{~K}\left(\mathrm{~Bq} \mathrm{~kg}{ }^{-1}\right)$ & ${ }^{232} \mathrm{Th}\left(\mathrm{Bq} \mathrm{kg}^{-1}\right)$ & ${ }^{238} \mathrm{U}\left(\mathrm{Bq} \mathrm{kg}{ }^{-1}\right)$ \\
\hline $120(2)$ & $3.9(1)$ & $7.1(2)$ \\
$\mathrm{K}(\%)$ & ${ }^{232} \mathrm{Th}(\mathrm{ppm})$ & $0.57(2)$ \\
$0.39(1)$ & $0.95(3)$ &
\end{tabular}

The highest integral areas from the main gamma transitions were noted under the peak at $1,460 \mathrm{keV}\left({ }^{40} \mathrm{~K}\right)$, and under the peaks at $351.9 \mathrm{keV}\left({ }^{214} \mathrm{~Pb}\right)$ and $609.3 \mathrm{keV}$ $\left({ }^{214} \mathrm{Bi}\right)$ (Table 3$)$. Compared to those, much smaller integrals were noted for the two most intense gamma transitions from the thorium series, i.e., at $911.6 \mathrm{keV}\left({ }^{228} \mathrm{Ac}\right)$ and $2614.5 \mathrm{keV}\left({ }^{208} \mathrm{Tl}\right)$. The gamma transitions at $2204.2 \mathrm{keV}$ showed the lowest count rates, ranging from $1.22 \times 10^{-3}$ (location 8) to $6.6 \times 10^{-3} \mathrm{\gamma} \mathrm{s}^{-1}$ (location 10). Despite the low yield (1.28\%) of the $2204.2 \mathrm{keV}$ transition [4], its contribution may be important to geoneutrino and similar experiments, because it may overlap with the deuteron binding energy of $2.2 \mathrm{MeV}$. This energy is released in gamma rays as a result of inverse beta-decay in a liquid scintillator [5]. Gamma fluxes at location 8 (measured with a collimator, Table 4 ) showed peaks on the order of $10^{-3}$ to $10^{-4} \gamma \mathrm{cm}^{-2} \mathrm{~s}^{-1}$ at most energy levels, and a peak on the order of $10^{-5}$ at $2204.2 \mathrm{keV}$. The gamma background radiation in the Boulby Underground Laboratory is lower than those observed in the Gran Sasso National Laboratory and the Laboratoire Souterrain de Modane [6, 7].

Laboratory measurements

The activity measurements for halite and mudstone (Fig. 6) are given in Table 5. The activity concentrations of ${ }^{232} \mathrm{Th}$ and ${ }^{238} \mathrm{U}$ were very low in both halite and mudstone, but they were significantly higher in mudstone than in halite. The average mudstone to halite ratios were 11,6 , and 18 for ${ }^{40} \mathrm{~K},{ }^{232} \mathrm{Th}$ and ${ }^{238} \mathrm{U}$, respectively (Table 5). The activity concentrations calculated directly during in situ measurements (location 8) were 112(2), 1.88(6), and $1.63(6) \mathrm{Bq} \mathrm{kg}^{-1}$ for ${ }^{40} \mathrm{~K},{ }^{232} \mathrm{Th}$, and ${ }^{238} \mathrm{U}$, respectively. These results indicated that the activity around the Lab resulted from a mixture of mudstone and halite activities.

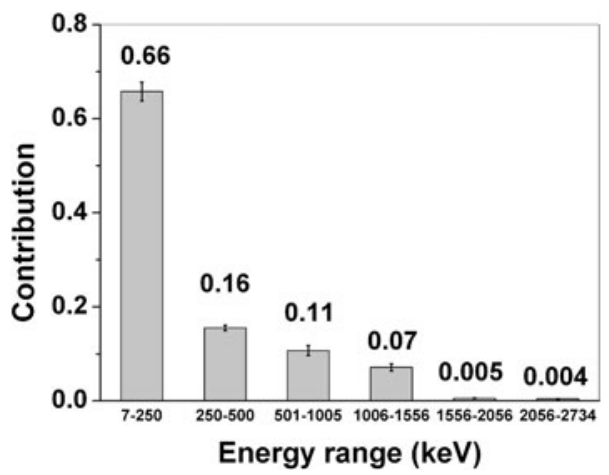

Fig. 5 Average fractional contributions of count rates in the different energy ranges at all locations
Fig. 4 a Count rates at specified locations inside the Lab. Thick solid line-average count rate. b Count rates at specified locations outside the Lab. Thick solid line-average count rate from the measurements taken without a collimator
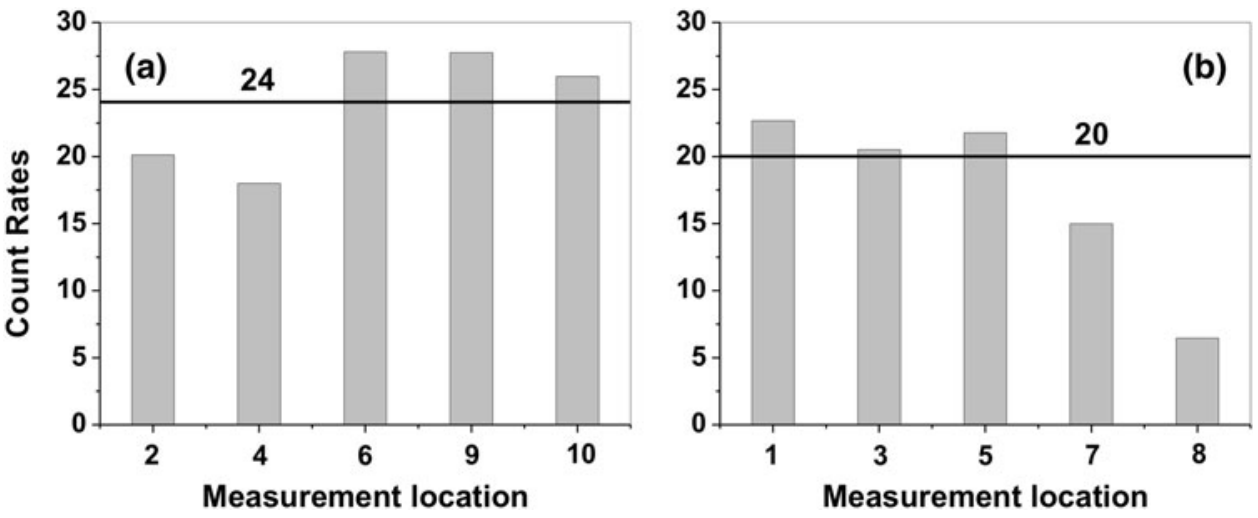
Fig. 6 a A photograph of a halite sample with its corresponding gamma-ray spectrum. b A photograph of a mudstone sample with its corresponding gamma-ray spectrum
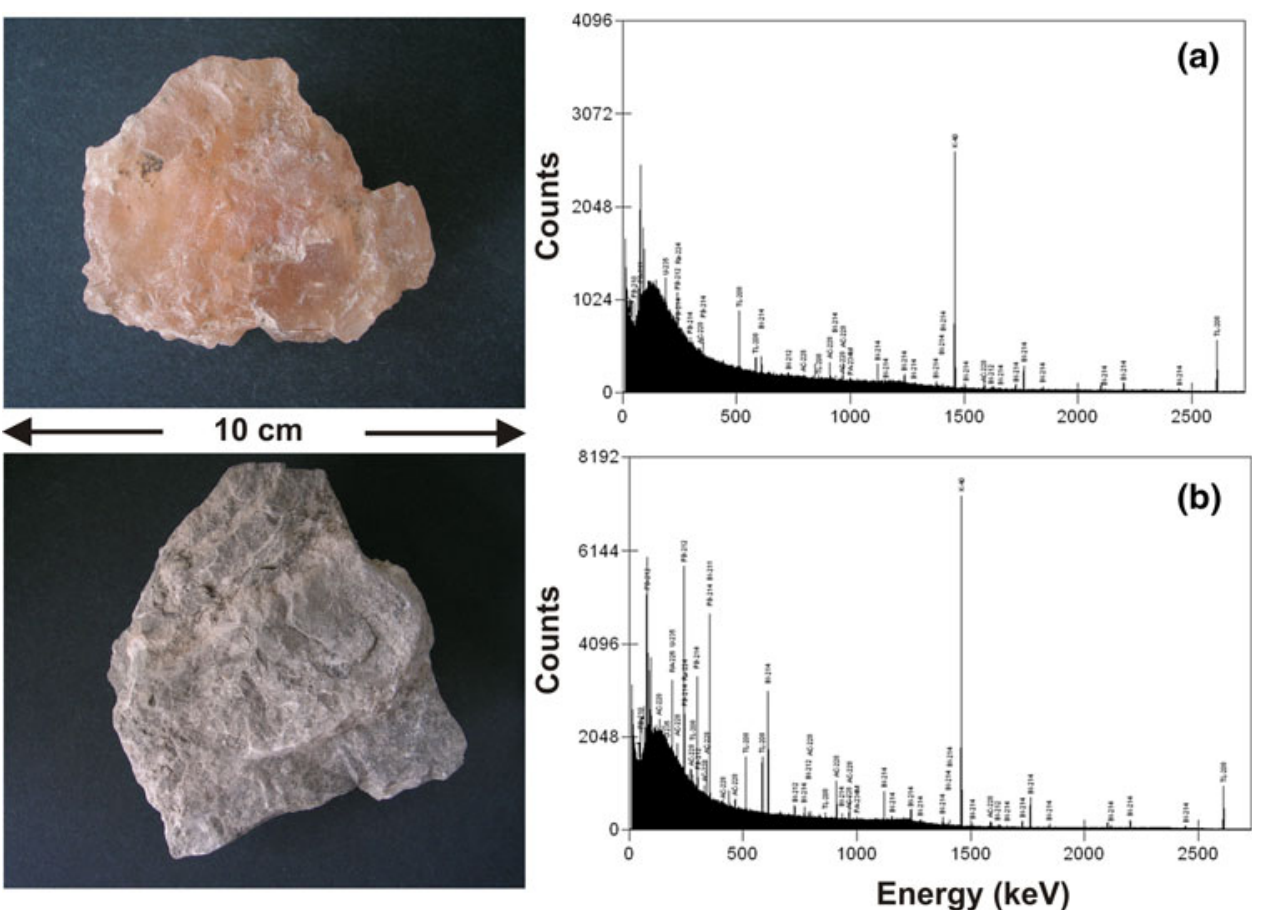

\section{Conclusions}

The gamma background was very low inside the Boulby Underground Laboratory. It was characterized by average count rates of $24 \gamma^{-1}$ in the energy range of 7-2,734 keV. The gamma flux outside the Lab was $0.128 \gamma_{\mathrm{cm}^{-2}} \mathrm{~s}^{-1}$. The construction materials and calibration sources inside the Lab did not contribute significantly to the total gamma background.

Acknowledgments This publication was supported by EU funds under the contract ILIAS RII3-CT-2004-506222.

Open Access This article is distributed under the terms of the Creative Commons Attribution License which permits any use, distribution, and reproduction in any medium, provided the original author(s) and the source are credited.

\section{References}

1. Miramonti L (2005) European underground laboratories: an overview. arXiv:hep-ex/0503054v1

2. Paling S (2006) Boulby Underground Laboratory. Boulby Underground Science Workshop: BUS-2006, York

3. Eisenbud M, Gesell T (1997) Environmental radioactivity from natural, industrial, and military sources. Academic Press, San Diego, pp 134-200

4. Firestone RB (1996) Table of Isotopes. Wiley-Interscience, Lawrence National Laboratory, Berkeley

5. Dye ST (ed) (2007) Neutrino geophysics. Springer, Dordrecht

6. Malczewski D, Kisiel J, Dorda J (2012) J Radioanal Nucl Chem 292:751-756

7. Malczewski D, Kisiel J, Dorda J (2013) J Radioanal Nucl Chem 295:749-754 